Camila Frabetti Campos de Oliveira ${ }^{1}$ Flora Maria Gomide Vezzáz

\section{A saúde dos músicos: dor na prática profissional de músicos de orquestra no ABCD paulista*}

\author{
Musicians' health: pain resulting from playing musical instruments \\ among members of orchestras of the ABCD region, São Paulo, Brazil
}

\begin{abstract}
${ }^{1}$ Discente, bolsista de iniciação científica do curso de Fisioterapia. Universidade Municipal de São Caetano do Sul.

2 Fisioterapeuta, docente da disciplina de Fisioterapia Preventiva e Laboral. Universidade Municipal de São Caetano do Sul.
\end{abstract}

*Trabalho de iniciação científica.

Contato:

Flora Maria Gomide Vezzá

Rua Álvares de Azevedo, 210/101

Centro - Santo André, SP

CEP: 09020-140

E-mail:

floravezza@usp.br
Recebido: 19/06/2009

Revisado: 07/02/2010

Aprovado: 09/02/2010

\section{Resumo}

Esta pesquisa averiguou a ocorrência de queixas dolorosas musculoesqueléticas relacionadas à prática de instrumento musical entre músicos de orquestras da região do ABCD paulista em 2008. Sessenta e nove músicos responderam ao Questionário Nórdico de Sintomas Osteomusculares (QNSO), complementado por um levantamento sociodemográfico. Foram levantadas as queixas nos últimos doze meses e nos últimos sete dias e os afastamentos das atividades habituais provocados por dor. Os dados foram tratados estatisticamente para uma descrição da amostra e análise da severidade dos casos. Os músicos pesquisados, 55 homens e 14 mulheres, constituíram um grupo jovem - 77\% abaixo de 35 anos - com um predomínio de instrumentistas de cordas, dos quais a maioria (72\%) tem dois ou mais vínculos de emprego. As queixas dolorosas atingem 65 dos 69 participantes, acometendo com maior severidade o tronco (regiões lombar e dorsal) e o punho: estas regiões, seguidas pelo pescoço, provocaram o maior número de afastamentos das atividades normais. Os resultados indicam que a dor "faz parte do negócio" entre os músicos. A dor dos músicos, como de outros trabalhadores, coloca na pauta a reflexão sobre como prevenir queixas dolorosas na perspectiva de uma atuação primária de promoção de saúde. Com relação à prevenção secundária, esta deveria ser feita em serviços de saúde preparados para lidar com as peculiaridades do trabalho do músico.

Palavras-chave: músicos; dor musculoesquelética; distúrbios osteomusculares relacionados ao trabalho.

\section{Abstract}

This study investigated the occurrence of musculoskeletal pain among orchestra musicians from the region of $A B C D$ (constituted by four industrial towns named Santo André, São Bernardo, São Caetano, and Diadema), in São Paulo state, Brazil, in 2008. Sixty-nine musicians filled the Nordic Musculoskeletal Questionnaire (NMQ) and gave information on demographic and professional aspects. Their complaints during the last 12 months and the last 7 days were registered, as well as their absence from professional activities due to pain. Data were treated statistically to describe the sample and assess severity of complaints. The assessed group - 55 men and 14 women, $77 \%$ under 35 years - was mostly formed by string musicians, $72 \%$ working for at least two orchestras. Sixty five of them reported pain that was more severe in the torso (lumbar or dorsal regions) and the wrist. These areas, followed by the neck, caused most of their absences from work. Results showed that pain is "part of musicians' job". The musician's pain, as well as other workers', raises the discussion on how it should be prevented in order to promote their health. Concerning secondary prevention, health services should be prepared to deal with musicians' occupational specificities.

Keywords: musicians; musculoskeletal pain; work related musculoskeletal disorders. 


\section{Introdução}

Desde o início do século XX, há relatos de distúrbios musculoesqueléticos relacionados ao exercício das atividades laborais que acometiam principalmente a coluna vertebral. No entanto, desde meados dos anos de 1980, houve uma mudança no tipo de problemas mais prevalentes. A partir deste período, a maior causa de afastamento e incapacidade temporária ou permanente está relacionada à ocorrência das chamadas LER/ DORT - Lesões por Esforços Repetitivos/Distúrbios Osteomusculares Relacionados ao Trabalho (KUORINKA; FORCIER, 1995). Este fenômeno foi observado em vários países e também no Brasil. O Ministério da Saúde reconhece que "dentre as doenças ocupacionais registradas, as LER/DORT são as mais prevalentes, segundo estatísticas referentes à população trabalhadora segurada”, de acordo com os dados do Instituto Nacional de Seguro Social em 1997 (BRASIL, 2001). Feuerstein (2005) aponta que o problema continua a crescer nos Estados Unidos.

A prática profissional ligada às artes também se insere neste panorama. Desde o início da década de 1980, vários países assistiram ao desenvolvimento de uma nova área de atuação das profissões da saúde, com a criação de várias associações dedicadas ao estudo de problemas de saúde de músicos e artistas performáticos (OSTWALD et al., 1994). Este desenvolvimento é uma resposta ao fato de que esta categoria profissional tem problemas de saúde específicos, relativos ao exercício de uma atividade artística que solicita o organismo de forma particular (ZAZA, 1998; ROYSTER; ROYSTER; KILLION, 1991; SCHUMAN et al. 2000), dentre os quais os distúrbios musculoesqueléticos são os mais frequentes (DEBÉS; SCHNEIDER; MALCHAIRE, 2003).

A prevalência de LER/DORT entre os músicos é comparável à dos trabalhadores industriais (ZAZA, 1998; BRANDFONBRENER, 2003; BRAGGE, 2006; BRAGGE et al., 2003; ALMEIDA, 1996, apud ANDRADE; FONSECA, 2000). Levantamentos epidemiológicos feitos por estes autores apontam também que os estudantes de música têm prevalências quase tão altas quanto os músicos profissionais, o que constitui grave problema de saúde pública, visto que este adoecimento atinge uma população jovem, que está no início de sua vida profissional. Zaza (1998), em uma revisão sistematizada de estudos epidemiológicos de problemas musculoesqueléticos relacionados à prática de um instrumento musical, verificou prevalências de $39 \%$ a $87 \%$ em músicos adultos e de $34 \%$ a $62 \%$ entre estudantes de música de nível secundário. Esta autora aponta que tal prevalência é comparável à de distúrbios osteomusculares relacionados ao trabalho (LER/DORT) de outros grupos ocupacionais.

No Brasil ainda são poucos os dados sobre tal fenômeno. A prevalência de sintomas de origem musculoesquelética entre os músicos da sinfônica de Londrina foi estudada por Trelha et al. (2004) e Andrade e Fonseca (2000) que investigaram a incidência de stress físico entre instrumentistas de corda. Não foram encontrados levantamentos sobre a incidência ou prevalência destes problemas entre estudantes.

Como é o caso com as LER/DORT, as causas destes distúrbios são multifatoriais e envolvem fatores profissionais, individuais e extraprofissionais. Costa (2003) fez a análise ergonômica da atividade de violistas e aponta características organizacionais do trabalho em orquestra que se relacionam à ocorrência de queixas musculoesqueléticas.

Os municípios da região do ABCD paulista vêm incentivando a música, através da implantação de orquestras sinfônicas e de escolas de música. Dados de divulgação das administrações públicas municipais fazem referência ao número de músicos que atuam em orquestras e bandas na região. À época da pesquisa (fevereiro de 2008), estes dados indicavam uma população em torno de 250 pessoas, de acordo com consultas às páginas oficiais das prefeituras da região ${ }^{3}$. No entanto, esta população não é fixa: com poucas exceções, os músicos não têm vínculo empregatício e recebem verbas de incentivo ou bolsas de estudo. Mudanças de administração provocadas por eleições ou substituição de quadros alteram o número de músicos financiados pelos municípios, segundo informações colhidas junto a representantes das orquestras ou de associações de músicos. Esta população está exposta a riscos ocupacionais que podem ser minorados através de ações de prevenção primária e secundária. Dada a relevância deste tipo de agravo à saúde e as consequências sociais deste acometimento, particularmente entre jovens estudantes de música, o objetivo deste estudo foi conhecer qual é o perfil de queixas de origem musculoesquelética entre músicos de orquestra da região do ABCD.

\section{Métodos}

Investigou-se a ocorrência de queixas dolorosas musculoesqueléticas entre membros de três orquestras sinfônicas e a Jazz sinfônica da região do ABCD através de um questionário autoaplicável. As orquestras foram visitadas pessoalmente durante os ensaios regulares e, na primeira visita, procedeu-se a uma palestra de esclarecimento sobre a pesquisa, exceto em uma delas, por falta de autorização do maestro. Neste caso,

${ }^{3}$ FUNDAÇÃO DAS ARTES DE SÃO CAETANO DO SUL. Disponível em: <http://www.fascs.com.br/1_3_1.asp?NKey=ORG001>. Acesso em: 09 fev. 2007. PREFEITURA MUNICIPAL DE DIADEMA. Disponível em:<http://www.diadema.sp.gov.br/>. Acesso em: 09. fev. 2007.

PREFEITURA MUNICIPAL DE SANTO ANDRÉ. Disponível em: <http:/www.santoandre.sp.gov.br/bn_conteudo.asp?cod=5952>. Acesso em: 09 fev. 2007. PREFEITURA MUNICIPAL DE SÃO BERNARDO DO CAMPO. Disponível em: < http://www.saobernardo.sp.gov.br/comuns/pqt_container_novo. asp?srcpg = noticia_completa\&ref=2322\&qt1 $=0>$. Acesso em: 09 fev. 2007. 
os músicos foram informados individualmente, ou em pequenos grupos, no horário de intervalo ou ao término do ensaio. Os questionários foram distribuídos em mãos antes, no intervalo ou após os ensaios e coletados pessoalmente no mesmo dia ou por ocasião de ensaios subsequentes da orquestra. Foram incluídos na amostra todos os integrantes da orquestra presentes nos ensaios e excluídos os maestros e o pessoal de apoio. Para obter um maior número de respondentes, cada orquestra foi visitada três vezes e 122 questionários foram distribuídos. Foram excluídas da amostra as bandas da região, por não serem bandas sinfônicas e utilizarem instrumentos diversos dos encontrados em orquestra. Todos os respondentes foram informados sobre os objetivos da pesquisa e consentiram livremente em participar após este esclarecimento. Foi utilizado como instrumento de coleta de dados o Questionário Nórdico de Sintomas Osteomusculares (QNSO) validado em português (PINHEIRO; TROCCOLI; CARVALHO, 2002), acrescido de um levantamento de dados demográficos e profissionais da população desenvolvido para esta pesquisa, que incluía o tempo de estudo do instrumento e a idade de início. O QNSO investiga: a frequência (nos últimos doze meses e nos últimos sete dias) de queixas em diferentes regiões do corpo (dor, dormência, formigamento ou desconforto); a relação das queixas com o trabalho; suas repercussões sobre as atividades rotineiras (trabalho, serviços domésticos ou passatempos), se foi necessário evitá-las devido a elas. Estabeleceu-se ainda uma classificação da intensidade de sintomas presentes nos últimos sete dias através da utilização de uma escala visual analógica de dor (EVA), que classifica a sensação dolorosa entre zero (nenhuma dor) e dez (dor intolerável). Os dados foram analisados através do sistema SAS (Statistical Analysis Software) para cálculo da frequência de quei- xas e sua severidade por região e para avaliação da relação destas com o trabalho.

O critério de severidade adotado foi aquele proposto por Pinheiro, Troccoli e Carvalho (2002), que varia de zero (ausência de sintomas, nenhuma diminuição das atividades normais) a quatro (queixas em 12 meses e em sete dias e prejuízo das atividades normais). Embora fosse possível discriminar entre queixas dolorosas à esquerda e à direita para os membros superiores, optamos por considerar cada articulação deste segmento bilateralmente.

\section{Resultados}

Foram distribuídos 122 questionários nas três orquestras sinfônicas, filarmônicas ou jazz sinfônica, todas na região do $A B C D$ paulista, e que realizam dois ensaios semanais, de 3 a 4 horas cada um. A taxa de resposta foi de $57 \%$ com 69 devolvidos. Quanto às características demográficas, 55 homens (80\%) e 14 mulheres (20\%) responderam ao QNSO, dos quais a maior parte pode ser considerada jovem: 53 (77\%) estão abaixo de 35 anos e 44 (62\%) têm entre 20 e 29 anos, conforme Gráfico 1.

Violinistas formaram o maior contingente (18 instrumentistas), seguidos por trombonistas (9) e flautistas (7), conforme o Gráfico 2. Dez músicos tocam um segundo instrumento. Se considerados por grupos de instrumentos, a amostra foi composta por 29 instrumentistas de cordas, 13 madeiras, 18 metais e 5 percussionistas. Os 4 músicos restantes tocam piano, violão ou guitarra.

Sessenta e um instrumentistas (88\%) classificaram-se como músicos profissionais, dois (3\%), como estudantes e seis (9\%) não responderam. Com relação ao vínculo empregatício, apenas 27\% (19 músicos) têm vínculo único;

Distribuição dos músicos por idade

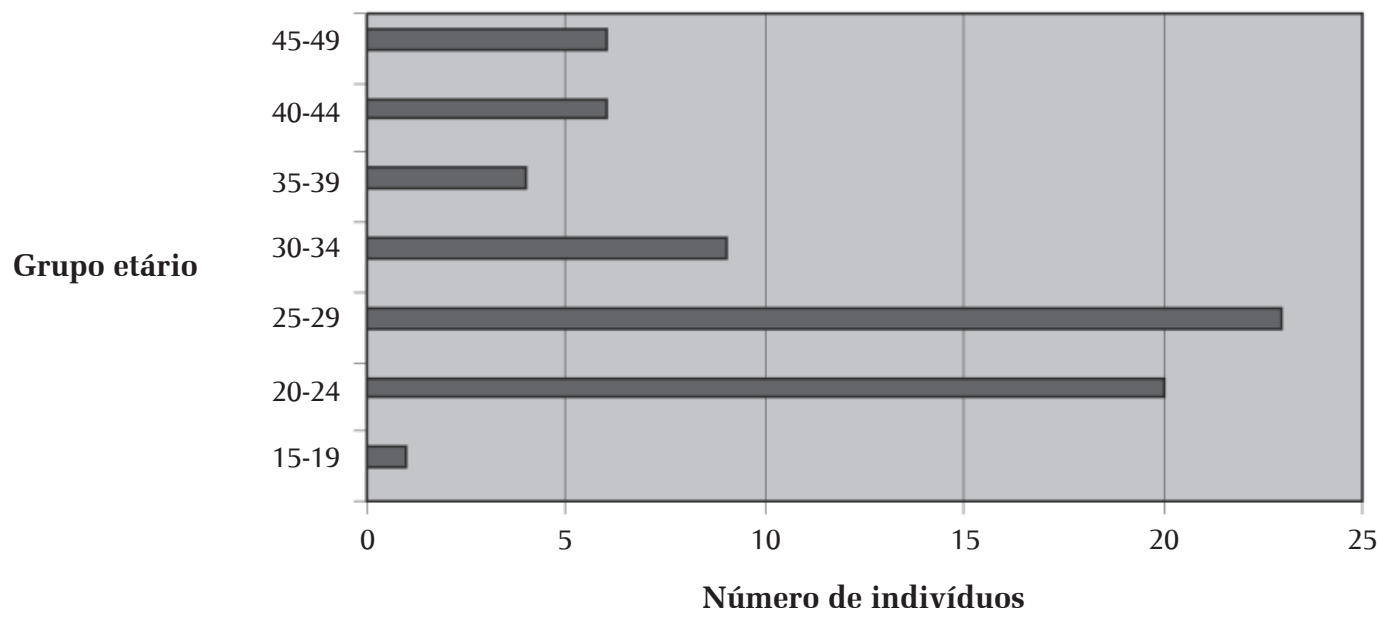

Gráfico 1 Distribuição por grupo etário dos músicos entrevistados, região do ABCD paulista, 2008 
os $72 \%$ restantes tocam em duas (29 músicos), três (17 músicos) ou 4 orquestras ( 2 músicos). Mais da metade (39 músicos) declarou tocar também em outros tipos de grupo musical, como grupos de serviços religiosos (casamentos, por exemplo). Apenas seis deles têm outra atividade remunerada fora das orquestras e grupos musicais: 4 são professores de instrumento e os outros 2 são proprietários de escola de música e professores de inglês.

A média de horas de estudo diário individual do instrumento é de 3,3h $\pm 1,5 \mathrm{~h}$ (Mediana $\mathrm{Md}=3$ horas). Quanto ao estudo diário em grupo, a média foi $4 \mathrm{~h} \pm$ $3 \mathrm{~h}(\mathrm{Md}=3 \mathrm{~h})$. Houve uma grande dispersão das estimativas deste último dado. Com relação ao tempo de prática do instrumento, a média foi de 14,9 anos $\pm 7,8$ $(\mathrm{Md}=14$ anos), sendo que 25\% deles toca há 18 anos ou mais e 34 instrumentistas (50\%) iniciaram o estu- do do instrumento entre 12 e 17 anos. Apenas 5 dos 69 músicos (7\%) afirmaram não ter tido nenhuma dor nos doze meses ou nos sete dias precedentes - uma trompa e quatro cordas.

A ocorrência de queixas por região é apresentada na Tabela 1 e a severidade dos sintomas relatados, na Tabela 2. O total de respostas varia, pois, sendo o questionário autoaplicável, muitos campos foram deixados em branco, com uma perda de respostas da ordem de $10 \%$. Quando discriminada a região do corpo, a área mais apontada foi o pescoço, tanto para doze meses (36 músicos) como para sete dias (22 músicos). A frequência de dor no tronco foi também bastante elevada, com 33 indicações para a região lombar e 30 para a região dorsal, tomando como referência os doze meses.

\section{Instrumento}

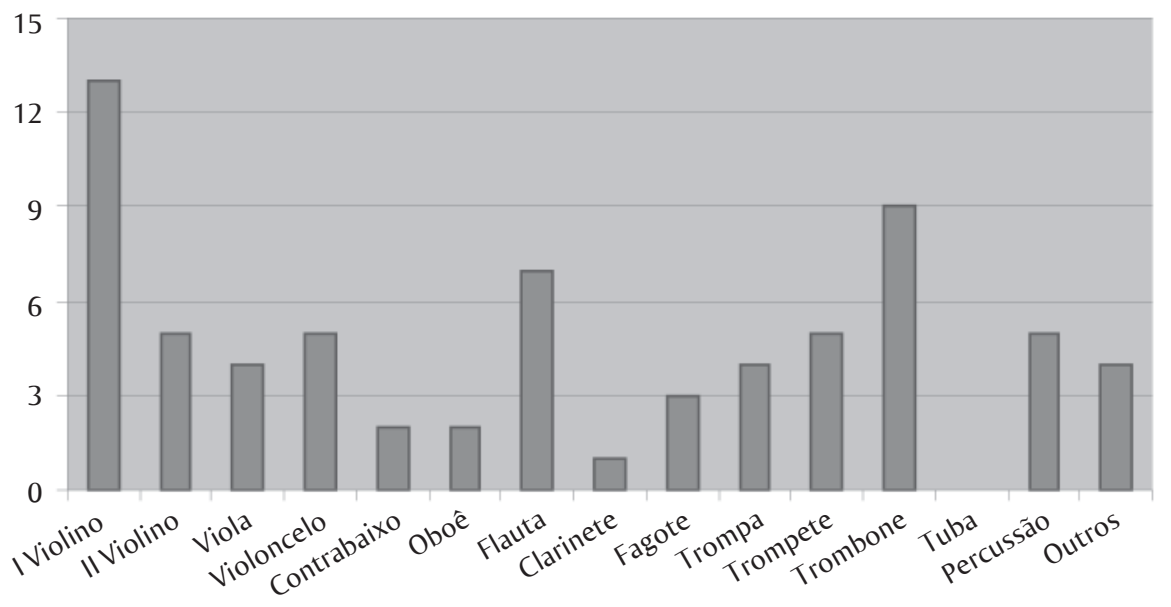

Gráfico 2 Distribuição por instrumento tocado pelos músicos entrevistados, região do ABCD paulista, 2008

Tabela 1 Frequência de respostas afirmativas à ocorrência de problemas (dor, formigamento ou desconforto) e redução do nível de atividades normais de trabalho, serviço doméstico ou passatempo entre a população de músicos entrevistados da região do ABCD paulista, 2008

\begin{tabular}{lcccccccccc}
\hline & Pescoço & Ombros & Cotovelos & Antebraços & $\begin{array}{c}\text { Punho, mão } \\
\text { ededos }\end{array}$ & $\begin{array}{c}\text { Região } \\
\text { dorsal }\end{array}$ & $\begin{array}{c}\text { Região } \\
\text { lombar }\end{array}$ & $\begin{array}{c}\text { Quadris } \\
\text { ou coxas }\end{array}$ & $\begin{array}{c}\text { Joelhos } \\
\text { Tornozelo } \\
\text { e pés }\end{array}$ \\
\hline $\begin{array}{l}12 \text { meses } \\
7 \text { dias }\end{array}$ & 36 & 31 & 5 & 15 & 26 & 30 & 33 & 8 & 8 & 4 \\
$\begin{array}{l}\text { Evitou ativi- } \\
\text { dades }\end{array}$ & 22 & 22 & 0 & 5 & 14 & 18 & 14 & 3 & 2 & 3 \\
\hline
\end{tabular}


Tabela 2 Frequência de severidade dos problemas relatados entre a população de músicos entrevistados na região do ABCD paulista, 2008

\begin{tabular}{|c|c|c|c|c|c|c|c|c|c|c|}
\hline & Pescoço & Ombros & Cotovelos & Antebraços & $\begin{array}{l}\text { Punho, mão } \\
\text { e dedos }\end{array}$ & $\begin{array}{l}\text { Região } \\
\text { dorsal }\end{array}$ & $\begin{array}{l}\text { Região } \\
\text { lombar }\end{array}$ & $\begin{array}{l}\text { Quadris } \\
\text { ou coxas }\end{array}$ & Joelhos & $\begin{array}{c}\text { Tornozelo } \\
\text { e pés }\end{array}$ \\
\hline 0 & 28 & 31 & 56 & 48 & 33 & 31 & 26 & 51 & 52 & 53 \\
\hline 1 & 10 & 7 & 3 & 7 & 11 & 10 & 16 & 3 & 3 & 2 \\
\hline 2 & 16 & 16 & 0 & 4 & 7 & 12 & 2 & 2 & 2 & 1 \\
\hline 3 & 5 & 1 & 2 & 1 & 2 & 0 & 1 & 0 & 0 & 0 \\
\hline 4 & 3 & 2 & 0 & 1 & 5 & 4 & 5 & 1 & 0 & 1 \\
\hline
\end{tabular}

$0=$ nenhuma queixa ou prejúzo de atividades; 1 = queixa em doze meses; 2 = queixas em doze meses E em sete dias; $3=$ queixa em doze meses OU em sete dias e prejuízo das atividades; 4 = queixa em doze meses E em sete dias e prejuízo das atividades (2008)

A relação das queixas dolorosas com o trabalho foi negada por apenas 11 dos participantes; 58 músicos atribuem suas causas à atividade profissional. As queixas dolorosas nos últimos sete dias, investigadas através da Escala Visual Analógica (EVA), apresentaram média de intensidade dolorosa de 3,6 $\pm 2,5$ $(\mathrm{Md}=4)$, sendo que $25 \%$ da amostra avaliaram sua dor como 5 ou mais.

\section{Discussão}

\section{Frequência geral e por região do corpo}

A ocorrência de queixas dolorosas na população de músicos estudada mostrou-se extremamente elevada, acometendo 64 músicos (93\%) em pelo menos um dos períodos investigados. Dados semelhantes, embora um pouco inferiores, foram observados por Trelha et al. (2004) em estudo da prevalência de queixas na Orquestra Sinfônica da Universidade de Londrina - 77,8\% de queixas em doze meses e 71,1\% em sete dias. Zaza (1998), em uma revisão sistemática de levantamentos epidemiológicos, encontrou prevalências variando entre 39\% e $87 \%$ de músicos adultos, e de $34 \%$ a $62 \%$ entre estudantes de música secundaristas.

Resultados semelhantes foram descritos por Trelha et al. (2004): entre as quatro regiões mais citadas naquele estudo, encontram-se ombros, coluna cervical, coluna dorsal, punhos e mãos.

Uma das dificuldades em comparar os estudos epidemiológicos entre si é devida a variações metodológicas, em particular à definição pobre do resultado observado (queixa dolorosa, disfunção...) (ZAZA, 1998).Em sete estudos listados sobre distúrbios musculoesqueléticos relacionados ao tocar, apenas três mensuraram queixas ou sintomas musculoesqueléticos: um estudo com 117 estudantes de piano de conservatório (GRIECO et al., apud ZAZA, op. cit.); um estudo comparativo entre 90 estudantes universitários de instrumento com um grupo controle de 159 pessoas (ROACH et al., apud ZAZA, op. cit.); e um estudo com 660 estudantes e funcionários de universidade de música (LARSSON et al., apud ZAZA, op. cit.). A prevalência destes dois últimos foi de $67 \%$, e entre os estudantes de piano, de $62 \%$. Os achados desta pesquisa são coerentes com o panorama delineado por estes estudos.

\section{Instrumento tocado}

Foi observada uma alta frequência de queixas para punho, mãos e dedos ao considerarmos o grupo das madeiras: em um grupo de 13 instrumentistas, 9 referiram queixas em doze meses, 3 em sete dias e 2 tiveram prejuízo de suas atividades normais por dores nesta região. No entanto, a amostra abordada e o tipo de coleta de dados não permitem que façamos inferências quanto à existência de um instrumento mais nocivo que outro com relação à produção de fenômenos dolorosos entre os instrumentistas das orquestras investigadas. Não parece haver consenso na literatura sobre um instrumento mais nocivo ou saudável. Hunter Fry, médico que estudou o acometimento de músicos na Austrália na década de 1980, verificou prevalência de 64\% entre 485 instrumentistas (apud MOURA; FONTES; FUKUJIMA, 2000) e apontou os violinistas e os violistas como os mais afetados pela sobrecarga muscular (apud ANDRADE; FONSECA, 2000). Brandfonbrener (1983, apud ANDRADE; FONSECA, 2000) aponta pianistas e instrumentistas de cordas entre os mais afetados.

Trelha et al. (2004) observou um maior predomínio de sintomas entre as cordas e os sopros, o que verificamos também em nossa amostra. No entanto, na comparação feita por Frank e Mühlen (2007), os violinistas apresentam porcentagens de queixas significativamente menores do que os instrumentos de sopro, como o fagote e a flauta transversal. 
As queixas dolorosas osteomusculares são fenômenos de causa multifatorial. Ao considerarmos as relações entre o adoecimento e o trabalho como músico, encontramos fatores de risco ligados aos aspectos físicos e ambientais, como as posturas determinadas pelo instrumento, o mobiliário adotado na orquestra (PRADO, 2006), mas também aspectos determinados pela organização do trabalho e pelas relações de emprego (COSTA; ABRAHÃO, 2004), além dos fatores individuais. Nas palavras de Frank e Mühlen (2007), "não é possível declarar algum instrumento como mais saudável" (p. 193), pois o estabelecimento de lesões está ligado a características individuais na interação física do corpo com o instrumento, como força muscular, dimensões corporais, posturas.

\section{Severidade e afastamento das atividades normais}

Em nosso levantamento, as três regiões que mais determinaram prejuízo das atividades habituais (trabalho, serviço doméstico ou passatempos) foram: pescoço (9 instrumentistas), punho, mão e dedos (8 instrumentistas) e região lombar (6 instrumentistas). Andrade e Fonseca (2000) observaram que 22,2\% músicos de sua amostra de instrumentistas de cordas relataram ter se afastado de sua atividade por desconforto nas costas e 17,9\%, no pescoço. Eles reportam um índice geral de afastamento de $30 \%$, embora não deixem claro se isto inclui todo o tipo de atividade ou se apenas a prática do instrumento. Índice semelhante, de 33,3\%, foi descrito por Trelha et al. (2004), sem que tenha sido discriminada a região de desconforto responsável.

Os baixos índices de afastamento, apesar da grande ocorrência de dores, têm sido atribuídos à relutância em interromper a prática do instrumento devido à preocupação com a excelência, a pressões derivadas da organização do trabalho na orquestra, como programação de apresentações e gravações, variação de repertórios, e também ao risco de perda de rendimentos (FRANK; MUHLEN, 2007; PEDERIVA, 2005; ANDRADE; FONSECA, 2000; COSTA; ABRAHÃO, 2004; ZAZA; CHARLES; MUSZYNSKI, 1998). Os múltiplos vínculos com diferentes orquestras encontrados por nós parecem corroborar estes argumentos.

Este fenômeno de continuar trabalhando apesar de queixas dolorosas é comum nas LER/DORT, mas sua interpretação requer reflexão. A busca de excelência artística, apontada por vários dos autores consultados, parece conviver com o fato de que a maioria das pessoas reluta em classificar suas dores como um problema de saúde, e a procurar ajuda, como destacam as cartilhas do Ministério da Saúde (BRASIL, 2001) a respeito das Lesões por Esforços Repetitivos/Distúrbios Osteomusculares Relacionados ao Trabalho (LER/DORT). O significado das dores para o músico, sua avaliação das dores como sendo "normais" ou como dores que podem ser classificadas como uma "doença” (ZAZA; CHARLES; MUSZYNSKI, 1998), também pode ser amplamente variável e interferir na decisão de afastamento. Finalmente, mas não menos importante, deve-se considerar que o acesso a serviços de saúde nem sempre é fácil, rápido ou barato, e que isto pode ter influência nos resultados obtidos, especialmente devido à falta de vínculo empregatício dos músicos.

\section{Número de horas de estudo}

O número de horas de estudo tem sido apontado como tendo um impacto significativo sobre as queixas (COSTA; ABRAHÃO, 2004; DEBÈS; SCHNEIDER; MALCHAIRE, 2003; FRANK; MUHLEN, 2007). Andrade e Fonseca (2000) consideraram este fator como determinante na interrupção de atividades. Os músicos por nós entrevistados referiram longos períodos diários de prática, tanto individual (média de aproximadamente $3 \mathrm{~h}$ ), como coletiva (média de $4 \mathrm{~h}$ ). Parece-nos que o vínculo múltiplo com orquestras diferentes, constatado em $72 \%$ dos músicos de nossa amostra, pode estar ligado tanto à ocorrência de queixas dolorosas quanto ao elevado número de horas de estudo, pois as orquestras trabalham repertórios diferentes, o que leva o instrumentista a preparar diferentes peças musicais para cada uma delas. Trelha et al. (2004) referem uma média de $31,85 \mathrm{~h} \pm$ 9,26 horas de atuação semanal na orquestra de Londrina. No entanto, estes autores não discriminaram entre prática individual e coletiva, nem investigaram a vinculação dos músicos de sua amostra com outros grupos musicais.

Além disso, o deslocamento do músico carregando seu instrumento, destacado por Frank e Muhlen (2007), como fator de risco de sobrecarga muscular, também se multiplica.

Andrade e Fonseca (2000) comparam a atuação do músico à atuação do atleta pela demanda de longas horas de prática e apresentações públicas nas quais o máximo de desempenho é exigido. A diferença reside no fato de que os atletas contam com especialistas atentos às características de sua saúde e dos agravos a ela infligidos pelo exercício profissional, e os músicos não.

\section{Características demográficas}

Algumas características demográficas da população estudada merecem destaque. A proporção de músicos por gênero em nossa amostra revelou um predomínio absoluto de indivíduos do sexo masculino (80\%), o que também foi visto no estudo de Londrina (TRELHA et al., 2004), com apenas 18\% de mulheres. Embora não seja possível afirmar que a proporção de mulheres nas orquestras do ABCD seja a mesma que a proporção por nós observada na população de estudo, as mulheres eram minoria em todos os ensaios visitados, o que está espelhado nos resultados levantados. Excetuando-se o levantamento de Heming (2004), que encontrou 51\% de homens em uma amostra de 59 músicos, os levantamentos consultados sobre músicos em outros países não indicam a proporção de mulheres entre músicos de orquestra, apenas referem que a gravidade dos problemas de saúde é maior entre as mulheres (FRANK; MÜHLEN, 2007; MOURA; FONTES; FUKUJIMA, 2000), podendo atingir uma relação de 3:1. Por estes resultados, Frank e Mühlen (2007) consideram o sexo um fator predisponente, o que seria devido à "menor força muscular, menor amplitude da mão e maior ocorrência de hipermobilidade articular entre mulheres [....]" (p. 191). 


\section{Considerações finais}

Os resultados encontrados neste estudo sugerem desconforto e dor bastante frequentes entre a população de músicos da região do ABCD. Distribuímos 122 questionários a todos os músicos presentes nos ensaios visitados. Desta população, 69 responderam, apresentando uma porcentagem de 93\% (64) de ocorrência de queixas. Mesmo que os que não responderam não apresentassem nenhuma queixa, estes 64 representam aproximadamente um quarto dos cerca de 250 músicos da região . A convivência com as queixas do sistema musculoesquelético parece fazer parte do cotidiano de muitos músicos e estes prosseguem em suas atividades profissionais com elas e apesar delas, como em outras categorias profissionais.

O profissional de saúde envolvido com a saúde dos trabalhadores deve estar atento às características deste trabalho, determinantes tanto dos riscos de adoecimento como do fracasso dos tratamentos. A busca de excelência artística, os constrangimentos induzidos pelas diferentes situações de trabalho às quais ele deve atender, a avaliação do próprio músico sobre suas queixas e seu significado devem ser objeto de reflexão para o profissional da saúde que quer não apenas "curar" um paciente, mas compreender o processo de adoecimento e prevenir novos agravos à saúde.

Os distúrbios musculoesqueléticos ocupacionais, de causas multifatoriais, exigem do profissional uma abordagem ampla, que vá além dos aspectos técnicos de tratamento do quadro físico e sintomático. Como para outras categorias, é necessário que se faça uma anamnese ocupacional detalhada dos músicos, bem como o levantamento de características do ambiente e do ritmo de trabalho, e de variações ligadas ao instrumento, ao exercício profissional, a características individuais. Estes aspectos podem estar envolvidos na instalação e desenvolvimento destas patologias e terão repercussões sobre o prognóstico e os resultados do tratamento.
Os músicos que apresentam queixas devem ter em mente que a atuação precoce é a melhor forma de enfrentá-las, antes que evoluam para um estágio crônico. Isto envolve atenção aos vários aspectos envolvidos na produção dos sintomas. Do ponto de vista da prevenção, são necessárias ações em dois níveis, o individual e o coletivo. O ambiente de trabalho deve ser modificado sempre que se mostrar inadequado, com atenção especial aos aspectos físicos: as cadeiras usadas na orquestra, bem como estantes, condições de iluminação e visualização das partituras, o que inclui a própria qualidade destas (COSTA; ABRAHÃO, 2004). A modificação destes aspectos demanda um esforço do coletivo de músicos, e não ações individuais.

Individualmente, os músicos devem estar atentos a si próprios, de forma a identificar os períodos de sobrecarga devido ao conjunto de suas atividades. Os efeitos da vida sedentária sobre o sistema musculoesquelético, como a perda de flexibilidade, os desequilíbrios musculares (fraqueza, por exemplo, de abdominais e tensão aumentada dos músculos da região lombar) provocados por períodos prolongados na postura sentada, não devem ser minimizados. Hábitos de saúde e atividade física, especialmente alongamento e relaxamento dos músculos encurtados e ativação dos grupos musculares inativos, auxiliam na prevenção de distúrbios dolorosos.

Na presença de queixas prolongadas e incapacitantes, o músico deve buscar tratamento adequado junto a profissionais habilitados. O profissional da saúde deve refletir sobre como preparar os músicos (mas não só eles) para enfrentar um ambiente potencialmente hostil, auxiliando-os a estabelecer neste ambiente uma relação que lhes dê maior controle sobre as agressões ao sistema musculoesquelético, reduzindo seus efeitos. Não se trata de minimizar o impacto do ambiente de trabalho ou de relações sociais de emprego, rendimentos e acesso a serviços de saúde sobre o bem-estar individual, mas da busca de uma intervenção de prevenção primária (esta quimera que perseguimos) que desperte a consciência corporal, a atenção ao gesto e ao movimento e que contribua para que os músicos mantenham-se no controle de suas condições de saúde.

\section{Agradecimentos}

Esta pesquisa foi realizada graças ao financiamento da Universidade Municipal de São Caetano do Sul, que concedeu bolsa de iniciação científica à discente e contratação em jornada da docente no ano de 2008. Agradecemos à colaboração de Marco Antonio Bussacos (Fundacentro) e Leandro Prearo (Inpes - USCS), pelo suporte estatístico, e à Dra. Leda Leal Ferreira (Fundacentro), pela grande amizade, incentivo e apoio.

\section{Referências}

ANDRADE, E. Q.; FONSECA, J. G. M. Artista-atleta: reflexões sobre a utilização do corpo na performance dos instrumentos de cordas. PER MUSI - Revista Acadêmica de Música, Belo Horizonte, n. 2, p. 118-128, jul./dez. 2000.
BRASIL. Ministério da Saúde. Departamento de Ações Programáticas e Estratégicas. Área Técnica de Saúde do Trabalhador. Lesões por esforços repetitivos (LER) e distúrbios osteomusculares relacionados ao 
trabalho (DORT). Brasília: Ministério da Saúde, 2001. (Série A. Normas e Manuais Técnicos, n. 103)

COSTA, C. P. Quando tocar dói: análise ergonômica de violistas de orquestra. 2003. 147 f. Dissertação (Mestrado em Psicologia)-Instituto de Psicologia, Universidade de Brasília, Brasília, 2003.

COSTA, C. P.; ABRAHÃO, J. I. Quando tocar dói: um olhar ergonômico sobre o fazer musical. PER MUSI - Revista Acadêmica de Música, Belo Horizonte, n.10, p. 60-79, jul./dez. 2004.

DEBÈS, I.; SCHNEIDER, M. P.; MALCHAIRE, J. Les troubles de santé des musiciens. Medicine du Travail et Ergonomie, v. 40, n. 3, p. 109-122, 2003.

FRANK, A.; VON MUHLEN, C. A. Queixas musculoesqueléticas em músicos: prevalência e fatores de risco. Revista Brasileira de Reumatolologia, São Paulo, v. 47, n. 3, p. 188-196, maio/jun. 2007.

HEMING, M. J. E. Occupational injuries suffered by classical musicians through overuse. Clinical Chiropractic, New York, v. 7, n. 2, p. 55-66, June 2004

KUORINKA, I.; FORCIER, L. (Eds). Work related musculoskeletal disorders (WMSDs): a reference book for prevention. New York: Taylor \& Francis, 1995

MOURA, R. C. R.; FONTES, S. V.; FUKUJIMA, M. M. Doenças ocupacionais em músicos: uma abordagem fisioterapêutica. Revista Neurociências, São Paulo, v. 8, n. 3, p. 103-107, 2000.

OSTWALD, P. F. et al. Performing arts medicine. The West Journal of Medicine, United States, v. 160, n. 1, p. 48-52, Jan. 1994.

PEDERIVA, P. L. M. O corpo no processo ensinoaprendizagem de instrumentos musicais: percepção de professores. 2005. 263 f. Dissertação (Mestrado em Educação)-Universidade Católica de Brasília, Brasília, 2005.

PINHEIRO, F. A.; TROCCOLI, B. T.; CARVALHO, C. V. Validação do questionário nórdico de sintomas osteomusculares como medida de morbidade. Revista de Saúde Pública, São Paulo, v. 36, n. 3, p. 307-312, jun. 2002.

PRADO, N. J. Avaliação da atividade de músicos de orquestra através da análise ergonômica do trabalho. 2006. Trabalho de conclusão de curso (Graduação em Fisioterapia)-Universidade Metodista de São Paulo, São Bernardo do Campo, 2006.

ROYSTER, J. D.; ROYSTER, L. H.; KILLION, M. C. Sound exposures and hearing thresholds of symphony orchestra musicians. The Journal Acoustic Society of America, United States, v. 89, n. 6, p. 2793-2803, jun. 1991.

SCHUMAN, J. S. et al. Increased intraocular pressure and visual field defects in high resistance wind instrument players. Ophthalmology, United States, v. 107, n. 1, p. 127-133, Jan. 2000.

TRELHA, C. S. et al. Arte e saúde: freqüência de sintomas músculo-esqueléticos em músicos da orquestra sinfônica da Universidade Estadual de Londrina. Semina: Ciências Biológicas e da Saúde, Londrina, v. 25, n. 1, p. 65-72, jan./jun. 2004.

ZAZA, C. Playing-related musculoskeletal disorders in musicians: a systematic review of incidence and prevalence. CMAJ: Canadian Medical Association Journal, Canadá, n. 158, v. 8, p. 1019-1025, Apr. 1998.

ZAZA, C.; CHARLES, C.; MUSZYNSKI, A. The meaning of playing-related musculoskeletal disorders to classical musicians. Social Science \& Medicine, England, v. 47, n. 12, p. 2013-2023, Dec. 1998. 